\title{
Cervical cytological study in unhealthy and healthy looking cervix
}

\author{
Neelam Pradhan, Kanti Giri, Ashma Rana \\ Department of Ob/Gyn TU Teaching Hospital
}

\begin{abstract}
Aim: To compare cervical cytology in women with healthy/unhealthy cervix.

Methods: A prospective study on Pap smear was performed including 200 women, 100 with healthy and 100 with unhealthy cervix, attending outpatient Gynaecology clinic of the Department of Ob/Gyn TU Teaching Hospital, Kathmandu. The cytology report was compared in the two groups.

Results: Cervical dysplasia was seen in 8 women with unhealthy cervix, 7 were mild and one was severe dysplasia. In the women with healthy cervix, 5 had mild and one had moderate dysplasia. Eighty two percent of women with healthy cervix and $83 \%$ of women with unhealthy cervix had non-specific inflammation.

Women who were married before 20 years $(p=0.04)$ and had higher parity $\left(3.3 V_{s} 2.8\right)$ were more likely to have unhealthy cervix $(p=0.03)$. Excessive vaginal discharge was common in women with unhealthy cervix $(p=0.0009)$.

Conclusion: Dysplasia was slightly higher among the women with unhealthy cervix in comparision to healthy cervix but the difference was not statistically significant. Hence this study emphasizes on the importance of universal screening of both the healthy and unhealthy looking cervix.
\end{abstract}

Key Words: carcinoma cervix, visual screening, Pap smear, cervical cytology, cervical dysplasia

\section{Introduction}

Carcinoma of the cervix continues to be a major public health problem all over the world, more so in developing nations as it significantly contributes to mortality and morbidity because of high prevalence rate and failure to early detection and inadequate treatment program in developing countries. It is the second most common carcinoma in women worldwide after carcinoma breast ${ }^{1}$ and ranks the fifth most common cancer after stomach, lung, breast and large bowel when malignancy in both males and females are taken together in the world. ${ }^{2}$

In Nepal, most of the studies done in hospitals indicate that the cancer scenario has not changed from what it used to be 10-20 years back until to day showing cancer of the cervix as the most common cancer in the female genital tract. ${ }^{3,4,5}$

Cervical cytology (Pap test) has remained one of the reliable methods for early detection of cervical intraepithelial neoplasia and carcinoma of cervix. The lowered incidence of this disease and related mortality in the developed countries has been attributed to routine Pap test leading to the detection of preinvasive and early invasive conditions and appropriate treatment. ${ }^{6}$

In Nepal still there is no universal screening. The women who attend gynaecology OPD with the complaints of vaginal discharge or who have unhealthy looking cervix are only screened routinely after a course of antibiotic or local vaginal antibiotic.

The women with healthy looking cervix are usually not routinely screened.

\section{Objective}

To perform Pap smear in the women attending Gynae OPD of TU Teaching Hospital having clinically healthy or unhealthy cervix and to compare the result of cytology in the two groups.

Correspondences

Dr. Neelam Pradhan, DGO, MSC (Epi) FCPS

Assoc Prof, Dept. of Ob/Gyn TUTH, Email: nseelam.44@gmail.com 
Table I. Demographic profile of women with healthy and unhealthy cervix ( $\mathrm{n}=100$ in each group)

\begin{tabular}{|c|c|c|}
\hline \multicolumn{3}{|c|}{ Age distribution } \\
\hline Age group & Healthy Cx & Unhealthy $\mathrm{Cx}$ \\
\hline$<20$ & 2 & 0 \\
\hline 20-29 & 23 & 20 \\
\hline $30-39$ & 26 & 38 \\
\hline $40-49$ & 32 & 30 \\
\hline$>50$ & 17 & 12 \\
\hline Mean age & $38.6+/-11.65$ & $38.1+/-9.88(\mathrm{p}$ value 0.74$)$ \\
\hline \multicolumn{3}{|c|}{ Age at marriage } \\
\hline$<20$ & 55 & 69 \\
\hline $20-29$ & 45 & 30 \\
\hline$>30$ & 0 & 1 \\
\hline Mean & $19.1+/-4.56$ & $18.5+/-3.64$ ( $\mathrm{p}$ value 0.30$)$ \\
\hline \multicolumn{3}{|c|}{ Age at first coitus } \\
\hline$<20$ & 56 & 68 \\
\hline $20-29$ & 44 & 31 \\
\hline$>30$ & 0 & 1 \\
\hline Mean & $19.3+/-4.06$ & $18.7+/-3.51(\mathrm{p}$ value 0.26$)$ \\
\hline \multicolumn{3}{|c|}{ Parity } \\
\hline 0 & 4 & 2 \\
\hline $1-2$ & 50 & 35 \\
\hline $3-4$ & 29 & 41 \\
\hline$>=5$ & 17 & 22 \\
\hline Mean & $2.8+/-1.65$ & $3.3+/-1.68(\mathrm{p}$ value 0.03$)$ \\
\hline
\end{tabular}

\section{Methods}

A prospective study with two comparison groups was undertaken in the Out Patient Department of Obstetrics and Gynecology of TU Teaching Hospital, Kathmandu over a period of 8 months. Each group included 100 clinically healthy looking cervix and 100 unhealthy looking cervix.

The unhealthy and healthy cervix was defined on the basis of naked eye observation of cervix on speculum examination. A healthy cervix was the one that looked pink, round, smooth with a central external Os.

The cervix was considered unhealthy if it had abnormalities present, either single or in various combinations such as hypertrophy, irregular, congested with increased vascularity or erosion, nabothian cysts and polyp or looked clinically suspicious for malignancy.

\section{Results}

Eighty three percent and $88 \%$ of the women with healthy cervix and unhealthy cervix were in the reproductive age group respectively. The age range was 18 to 73 years and 22 to 72 years in healthy and unhealthy cervix group respectively.

Women having unhealthy cervix were more likely to get married before the age of $20 \mathrm{yrs}(69 \%$ vs to $55 \%)$ than the women with healthy cervix $(\mathrm{P}<0.05)$. The age at marriage ranged from 7 to 29 years and 12 to 31 years in the healthy and unhealthy cervix group respectively. Table 1 shows that women who had their first sexual contact before the age of 20 were more likely to have unhealthy cervix (68\% vs 56\%). The difference was however not significant $(\mathrm{p}=0.08)$. The age at first coitus ranged from 12-29 yrs in the healthy and 12-31 yrs in the unhealthy cervix group. 
Table 2. Characteristics of women with healthy cervix and abnormal Pap smear $(n=6)$

\begin{tabular}{cccccc} 
SN & Age & Age at marriage & Age at $1^{\text {st }}$ coitus & Parity & Pap result \\
\hline 1 & 48 & 16 & 16 & 4 & Mod dys \\
2 & 29 & 14 & 17 & 4 & Mild dys \\
3 & 26 & 22 & 22 & 2 & Mild dys \\
4 & 36 & 23 & 23 & $2+1$ & Mild dys \\
5 & 41 & 16 & 16 & 3 & Mild dys \\
6 & 40 & 19 & 19 & 2 & Mild dys \\
mean & 36.6 & 18.3 & 18.8 & 2.8 & \\
\hline
\end{tabular}

Unhealthy cervix was more common finding in women of higher parity ( $>=3$ children) than in women of lower parity (63\% vs $46 \%)$ and vice versa showing healthy cervix less common in higher parity women compared to lower parity ie, $37 \%$ vs $54 \%(\mathrm{p}=0.01)$.

Four out of 6 women among the healthy cervix group and 5 out of 8 women among the unhealthy cervix group having dysplasia had sexual contact before 20 years of age and all of them were married before the age of $20 \mathrm{yrs}$. Three out of six women among the healthy cervix group and 6 out of 8 women among the unhealthy cervix group having dysplastic change in the cervix had 3 or more children.

A history of excessive vaginal discharge was more often present in women who had unhealthy cervix (44) than healthy cervix (22) p 0.0009 . Post coital bleeding was also two times more in women who had unhealthy cervix (8) than healthy cervix (4) but was not significant.

Out of 100 women in each group in whom Pap smear was taken, 6 had dysplasia in healthy cervix group and 8 had dysplasia in unhealthy cervix oup. The difference was statistically not significant $(p=0.78)$. Among the women having healthy cervix, 5 had mild and 1 had moderate dysplasia. Severe dysplasia was present in a woman with unhealthy cervix, the remaining were mild dysplasia. The majority of women, $82 \%$ among the healthy cervix group and $83 \%$ among the unhealthy cervix group had an inflammatory smear.

\section{Discussion}

Organized cytology screening is the mainstay for early detection of preinvasive and invasive lesion. Though a regular pap test in sexually active women is recommended to reduce morbidity and mortality from cancer cervix this has not been feasible yet in our country due to scanty resources and lack of awareness. Since there are reports suggesting, even the healthy looking cervix can have cytological abnormality this study was done to compare the results of pap smear among women with healthy and unhealthy cervix and factors that influence on the visual look of the cervix.

The mean age of women having dysplasia was 36.6 years for healthy cervix and 44.6 years for unhealthy cervix. According to epidemiological studies, the most common age to develop carcinoma cervix is between

Table 3. Characteristic of women with unhealthy cervix and abnormal pap smear $(n=8)$

\begin{tabular}{ccccccc}
\hline SN & Age & $\begin{array}{c}\text { Age at } \\
\text { marriage }\end{array}$ & $\begin{array}{c}\text { Age at } \\
1^{\text {st coitus }}\end{array}$ & Parity & Clinical look & Pap result \\
\hline 1 & 46 & 12 & 12 & 8 & Irreg, hyper & Mild dys \\
2 & 42 & 15 & 15 & 5 & Irreg hyper erosion & Sev dys \\
3 & 32 & 18 & 18 & 4 & Erosion, hyper & Mild dys \\
4 & 46 & 22 & 22 & 3 & Irreg, hyper, naboth cyst & Mild dys \\
5 & 72 & 12 & 18 & 7 & Vascular bleeds, cong & Mild dys \\
6 & 44 & 31 & 31 & 2 & Hyper, cong & Mild dys \\
7 & 30 & 29 & 29 & 0 & Cong, erosion & Mild dys \\
8 & 45 & 16 & 16 & 6 & Polyp & Mild dys \\
mean & 44.6 & 19.4 & 20.1 & 4.4 & & \\
\hline
\end{tabular}

Bleeds = bleeds on touch, cong= congested, dys =dysplasia, Hyper $=$ hypertrophied, Irreg= irregular, mod $=$ moderate, $N=$ normal, Naboth $=$ nabothian, sev=severe 
Table 4. Relevant Clinical history in the women with healthy and unhealthy cervix

\begin{tabular}{ccc}
\hline History & Healthy cervix $(\mathrm{n}=100)$ & Unhealthy cervix $(\mathrm{n}=100)$ \\
\hline 个vaginal discharge & 22 & 44 \\
Post coital bleeding & 4 & 8 \\
Smoking & 11 & 12 \\
Family history of cancer & & 1 \\
Cervix & 2 & 1 \\
Breast & 1 & 2 \\
Others & 2 & 2 \\
\hline
\end{tabular}

40 and 50 years and the precursors of cervical cancer occur 5 to 10 years prior to the development of invasive cancer. ${ }^{7}$ Thus, mean age of dysplasia in this study was similar to the above studies.

Dysplasia is not said to be common in older women. ${ }^{8}$ Similarly mild dysplasia was seen only in one woman of 72 years in this study. In the study by Wijngaarden and Duncan, dysplasia of grade I was detected only once after age 50. ${ }^{9}$ Therefore Stjernsward and associates have recommended that screening of women between 35 and 55 years of age would be most valuable. ${ }^{10}$

In the present study, women who were married and had begun their sexual activity before 20 years of age were more likely to have an unhealthy cervix. Unhealthy cervix was also more common among the women with 3 or more children. Repeated childbirth may cause injury to cervix and erosion and cervicitis are also common in multipara, which can give cervix an abnormal appearance as remarked by Sir Norman Jeffcoate. ${ }^{11}$

Women who had dysplasia in this study were already married and had begun the sexual activity before the age $20 \mathrm{yrs}(4 / 6$ and 5/8 among healthy and unhealthy cervix grp) supporting the existing relation between coitus and dysplasia. With the beginning of sexual activity there are chances of introduction of oncogenic factors like sperm and HPV. Women of young age group are more vulnerable because, cervical cells in the SCJ and $\mathrm{TZ}$ are immature and in active phase of metaplasia and are more susceptible to oncogenic stimuli. ${ }^{12}$ Women with dysplasia were also more likely to have higher parity (3/6 among healthy cervix group and 6/8 among unhealthy cervix had 3 or more children) indicating relationship with duration of sexual exposure and dysplasia.

Excessive vaginal discharge was more common in women having unhealthy cervix (44) than the women having healthy cervix (22), $\mathrm{p}<0.05$. Similarly, 8 women with unhealthy cervix compared to 4 women with healthy cervix gave history of contact bleeding. Out of these 8 women with unhealthy cervix, 5 had huge erosion, 2 had inflamed and congested cervix, while 1 had a cervical polyp explaining the cause of excessive discharge and PCB in these women. Increased vaginal discharge and contact bleeding can occur in conditions like erosion and inflammation, due to increased vascularity and hypertrophy of glandular tissue resulting in over activity and also due to exposure of cervical glandular crypts in erosions. ${ }^{11}$

Table 5. Comparison of cytological report obtained from Pap smear in women with healthy and unhealthy cervix

\begin{tabular}{lcc}
\hline Cytology & Healthy cervix $\mathrm{n}$ & Unhealthy cervix n \\
\hline Normal & 10 & 6 \\
Non specific Inflammation & 82 & 83 \\
Mild atypia & 2 & 3 \\
Dysplasia & & \\
Mild & 5 & 7 \\
Moderate & 1 & 0 \\
Severe & 0 & 1 \\
Total & 100 & 100 \\
\hline
\end{tabular}


Majority of the women in both groups had non specific inflammation in the cytology report, $82 \%$ in healthy cervix group and $83 \%$ in unhealthy cervix group. According to Sir Norman Jeffcoate, cervicitis is a common finding in nearly all multiparous women and in many nulliparous women as well. ${ }^{11}$ This could be the reason for inflammatory report in most of the Pap smear test in this study as majority of women had at least one child.

Pap smear of 2 women in the healthy and 3 in the unhealthy cervix group had atypia. Atypia is considered a benign condition, often confused with intraepithelial neoplasia, which occur in cases of severe, acute, and long-standing chronic inflammation or infection. It can also occur with epithelial injury of any kind, such as erosion, biopsy or conization as a reparative process. ${ }^{13,14}$ All the 3 women with unhealthy cervix had inflammatory cells as well while one of the smears in healthy cervix had squamous metaplasia indicating a reparative process and the other had inflammatory cells explaining the cause of atypia in these women. The significance of the diagnosis of atypia in cytology is not very clear. The British Society for Clinical Cytology recommends a repeat smear, only in cases of severe inflammation after few months or after treatment when trichomonas, candida, or gardnerella are seen. If atypia is present on repeated examination, follow up Pap smear with colposcopy is recommended. ${ }^{15}$ Some authors recommend biopsy in addition to colposcopy when such atypia is encountered because the rate of occurrence of dysplasia ranged from $10.1 \%$ to $57 \%$ after diagnosis of atypia. ${ }^{13}$ In this study, all of the women who had atypia, also had inflammation and were between 35 and 50 years of age, a risky age group for the development of $\mathrm{CIN}$ and cervical carcinoma. ${ }^{7}$ So, keeping in view of the above authors follow up with repeat smear or repeat smear after treatment would benefit these women.

In the present study dysplasia was seen in slightly higher number of women $(8 / 100)$ in unhealthy cervix group compared to women in healthy cervix group (6/ $100)$. But the difference was not significant statistically. Many authors have directed their focus on the look of cervix as higher grades of dysplasia and malignancy were confined in the unhealthy cervix. ${ }^{16,17,18}$

But they also commented that visual screening was inferior to cytology or colposcopy as it detected only $63 \%$ of abnormality in comparison to $71 \%$ by cytology or colposcopy and concluded that visual screening would still be useful where cytological screening is not feasible. ${ }^{16}$

Similarly Misra and colleagues reported $11.2 \%$ cervical dysplasia and $1.9 \%$ malignancy in cytology of unhealthy cervix compared to $3.3 \%$ dysplasia and $0.02 \%$ malignancy in healthy cervix. ${ }^{17}$ In the present study too, dysplasia of moderate grade was seen in a woman with healthy cervix while severe dysplasia was seen in a woman with unhealthy cervix. This indicated association of normal look of the cervix with lower grade of lesion and abnormal look with higher grade of lesion as the above authors.

But in the study by Sehgal and associates, which screened 11,760 women clinically and cytologically, only $41 \%$ of the cervix, which looked suspicious clinically, were positively associated with abnormal cytology. Cytology detected $71 \%$ and colposcopy detected $87 \%$ of the abnormalities irrespective of clinical look. Therefore they concluded that screening based only on visual examination is inferior to cytological screening. ${ }^{19}$

Similarly in a small study of Pap test done in 100 women, dysplasia was seen in 7 women with clinically normal looking cervix 6 in cervicitis, 1 each in atrophic uterus and cervical polyp. ${ }^{20}$ The result was almost similar to this study. Many other authors have also found dysplasia occurring in majority of healthy cervices.

\section{Conclusion}

As not much difference was noted in the number of abnormal cytology whether the cervix was healthy or unhealthy, it can be derived that cytological change is is difficult to predict by simply looking at the cervix. There is thus no definite clinical impression to suspect cases of dysplasia. Dysplasia was seen in quite a number of healthy cervices. Therefore, it is necessary for all sexually active women to undergo cytological evaluation whether the cervix looks healthy or not.

\section{References}

1. Parkin DM, Laara E, Muir CS. Estimates of the worldwide frequency of sixteen major cancers in 1980. Int J Cancer. 1988; 41; 184.

2. Armstrong BK, Munoz N, Bosch FX. Epidemiology of cancer of the cervix. In: Coppleson M (Ed), Monagham JM, Morrow CP, Martin HN TS (Assoc Eds) Gynaecologic Oncology. $2^{\text {nd }}$ edn. New York. Churchill Livingstone, 1992; 11-29.

3. Gurubacharya VL, Shrestha HG. Cancer of breast and female genital tract in Nepal. J of Nepal Medical Association 1980:18(1): 43-50.

4. Shrestha HG. Incidence of cancer in Nepal. Presented in $3^{\text {rd }}$ congress of Asia Pacific association of societies of pathologists \& $11^{\text {th }}$ national convention Bangladesh 1993. 
5. Shrestha MM, Pradhananga KK. Hospital based cancer registry and prevalence of cancer in Nepal. J Nep Med Assoc 1997; 36:289-295.

6. Shrestha HG, Dali S et al. Present cancer scenario and its changing pattern at TU Teaching hospital, Nepal. J Nep Med Assoc 1997; 35:45-51.

7. Bishop A, Wells E, Sherris J, Tsu V, Crook B. Cervical cancer: Evolving prevention strategies for developing countries. Reproductive Health Matters Nov 1995; 6:60-71.

8. Fletcher A. Screening for cancer of the cervix in elderly women. The Lancet; Jan 1990; 335: 97-99.

9. Wijngaarden WJV, Duncan ID. Rationale for stopping cervical screening in women over 50 . BMJ April 1993; 306: 967-71.

10. Stjernsward J, Eddy D, Luthra U, Stanley K. Plotting a new course for cervical cancer screening in developing countries. World Health Forum.1987; 8; 42-45.

11. Jeffcoate N. Tumours of the cervix uteri. In: Bhatla N (eds) Jeffcoate's Principles of Gynaecology. $6^{\text {th }}$ edn. London. Arnold, 2001; 44765 .

12. Hatch KD, Hacker NF. Intraepithelial disease of the cervix, vagina and vulva. In: Berek JS, Adashi EY, Hillard PA (Eds). Novak's Gynecology. 12 edn. Baltimore, Williams and Wilkins, 1996; 447486.

13. Karen M Atkinson. Specimen collection and determinants of adequacy. In: Bonfiglio TA and Erozan YS. (eds) Gynaecologic Cytopathology. Philadelphia, Lippincott-Raven, 1997; 7- 18.

14. Wright TC, Ferenczy A. Benign diseases of the cervix. In: Kurman R J (Ed) Blaustein's Pathology of the female genital tract. $4^{\text {th }}$ edn. London. Springer-Verlag, 1994; 203-227.

15. Evans DMD, Hudson EA, Brown CL, et al. Terminology in gynaecological cytopathology: report of the working party of the British Society for clinical cytology. J Clin Pathol 1986; 39: 93344.

16. Singh V, Sehgal A, Luthra UK. Screening for cervical cancer by direct inspection. BMJ Feb 1992; 304: 534-35.

17. Misra JS, Das K, Chandrawati. Results of clinically downstaging cervical cancer in a cytological screening programme. Diagn Cytopathol Nov 1998; 19(5): 344-8.

18. Sujathan K, Kannan S et al. Implications of gynaecological abnormalities in pre-selection criteria for cervical screening: preliminary evaluation of 3602 subjects in South India. Cytopathology Apr 1995; 6(2): 75-87.

19. Sehgal A, Singh V, Bhambhani S, Luthra UK. Screening for cervical cancer by direct inspection. Lancet Aug1991; 338(8762):282.

20. Shrivastava V, Bhanot UK. Prospective study of 100 cases of Pap smear. J Nep Med Assoc 1998; 37 (128):635-40. 